\title{
Influence of Drying on Accelerated Carbonation Testing of Concrete
}

\author{
Jean Louis Gallias ${ }^{1}$, Bruno Fiorio ${ }^{1}$, Yunyun Tong ${ }^{2}$ and Mehdi Benaissa ${ }^{1}$ \\ ${ }^{1}$ Laboratory of Materials and Mechanics of Civil Engineering (L2MGC), University of Cergy- \\ Pontoise, 95000, Cergy-Pontoise France, jean-louis.gallias@u-cergy.fr \\ ${ }^{2}$ School of Architecture and Civil Engineering, Zhejiang University of Science \& Technology, \\ 310023, Hangzhou, China, 2195838307@qq.com
}

\begin{abstract}
The aim of this work is to better understand the influence of drying conditions and moisture content of concrete on the carbonation kinetics during accelerated tests. Cylindrical specimens of a typical concrete formulation for buildings were dried, after 28 days wet curing, under three different conditions: $80^{\circ} \mathrm{C}, 45^{\circ} \mathrm{C}$ and $20^{\circ} \mathrm{C}$ and $50 \% \mathrm{RH}$. The carbonation depth and the height of water absorption were measured during 70 days testing under $3 \% \mathrm{CO}_{2}, 20^{\circ} \mathrm{C}$ and $65 \% \mathrm{RH}$. The results show that there is a significant difference in the drying behavior of cylindrical specimens between the lateral cast surface and their circular free surface. But, the drying cycle before accelerated carbonation tests has more influence on the carbonation rate than the type of exposed surface.
\end{abstract}

Keywords: Concrete, Drying, Accelerated Carbonation Test, Water Absorption.

\section{Introduction}

Natural carbonation of concrete is one of the main reasons of steel reinforcement corrosion. The moisture conditions of concrete exposure have an important impact on carbonation kinetics. According to NF EN 206 (2014) standard, environments with medium relative humidity (between 50 and $70 \%$ ) induce higher carbonation of concrete than drier or damper environments.

Accelerated tests are generally carried out to determine carbonation resistance of concrete and to assess the influence of various parameters of formulation, curing or ageing (Fattuhi, 1988; Alahmad et al., 2009) Varying experimental conditions are used for the tests. In European level, there is not consensus for accelerated carbonation tests. For example, the Belgian standard recommends exposure of concrete specimens to $1 \% \mathrm{CO}_{2}$ while the French standard (NF XP P18-458, 2008) recommends 50\% $\mathrm{CO}_{2}$. The conditioning of specimens before $\mathrm{CO}_{2}$ exposure varies even more strongly. For example, the European project of standard (prTS 12390-12, 2010) recommends 14 days drying in room conditions while the French standard recommends 14 days drying at $45^{\circ} \mathrm{C}$. Different drying conditions before testing lead to different moisture content of concrete and consequently to varying carbonation kinetics (Parrott, .1996) (Galan, 2013).

The aim of the present work is to better understand the influence of drying conditions and moisture content of concrete on its carbonation kinetics during accelerated test.

\section{Materials and Methods}

A formulation of concrete with $275 \mathrm{~kg} / \mathrm{m}^{3}$ of CEM II/A-LL $42.5 \mathrm{R}$ cement (according to EN 197.1 standard), 0.7 water-cement ratio and siliceous aggregates was used for the tests (Table 
1). The compressive strength at 28 days was $26 \pm 2 \mathrm{MPa}$ and the density $2367 \pm 10 \mathrm{~kg} / \mathrm{m}^{3}$. The formulation is representative of that used in France for building constructions in 50's and 60 's presenting today many problems of reinforcement corrosion.

Table 1. Composition of concrete.

\begin{tabular}{cc}
\hline & $\mathrm{kg} / \mathrm{m}^{3}$ \\
\hline CEM II/A LL 42.5R & 275 \\
\hline Sand 0/4 & 833 \\
\hline Coarse aggregate 4/16 & 1062 \\
\hline Water & 193 \\
\hline
\end{tabular}

Cylindrical $\varnothing 11 \times 22 \mathrm{~cm}$ specimens were prepared and cured under water till 28 days. At 28 days, they were sawed into $\varnothing 11 \times 7 \mathrm{~cm}$ specimens including the free surface of concrete of initial cylinders and into $\varnothing 11 \times 11 \mathrm{~cm}$ specimens which excluded the bottom of the initial cylinders. The $\varnothing 11 \times 7 \mathrm{~cm}$ specimens were covered with aluminum sheet in order to expose only the circular free surface of concrete of the initial cylinders. The $\varnothing 11 \times 11 \mathrm{~cm}$ specimens were also covered with aluminum sheet in order to expose only the lateral cylindrical cast surface. With this setup, it could be expected that the free surface of specimens is representative of the free surface slabs and the cast surface of specimens is representative of cast surface of columns, beams or shells in buildings.

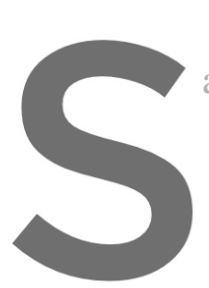

Both types of specimen

accelerated carbonation

14 days at 80

14 days at 45

- 87 days at 20

The drying at $45^{\circ} \mathrm{C}$
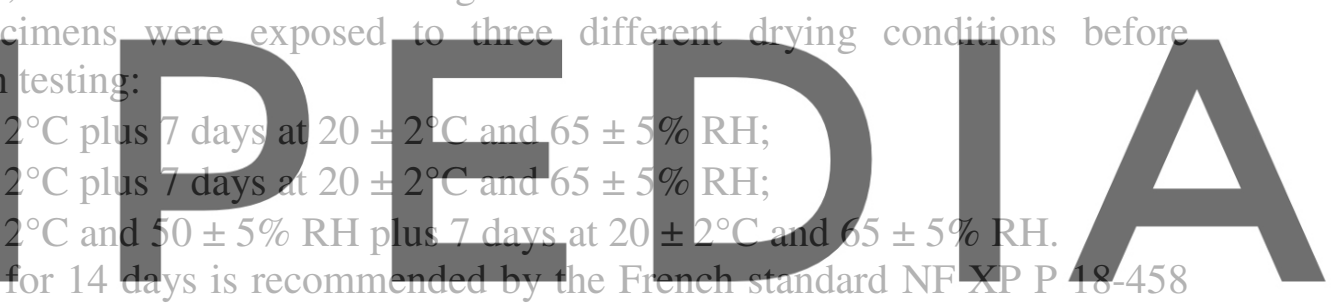

(2008) for accelerated carbonation tests on concrete. The drying at $20^{\circ} \mathrm{C}$ and $50 \% \mathrm{RH}$ for 87

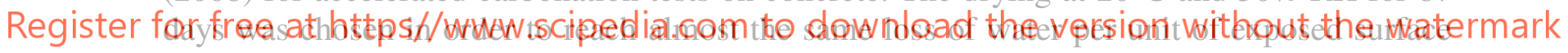

then that obtained in 14 days at $45^{\circ} \mathrm{C}$. The drying at $80^{\circ} \mathrm{C}$ was applied to obtain strong and deep drying of the surface layer of concrete even if the concrete microstructure could be modified. A complementary drying for 7 days at $20^{\circ} \mathrm{C}$ and $65 \% \mathrm{RH}$ was applied in all cases in order to stabilize moisture content of concrete in the same hydrothermal conditions than that used during accelerated carbonation tests. In fact, after drying, accelerated carbonation tests were carried out in $3 \% \mathrm{CO}_{2}, 20 \pm 2{ }^{\circ} \mathrm{C}$ and $65 \pm 5 \% \mathrm{RH}$ for 70 days. According to Auroy et al. (2018), 3\% CO2 is representative of natural carbonation. On the other hand, the hydrothermal conditions of accelerated tests are those of the French standard and close to those of the project of European standard prTS 12390-12 (2010): $20 \pm 2{ }^{\circ} \mathrm{C}$ and $55 \pm 5 \% \mathrm{RH}$.

The carbonation depth was measured at $0,28,56$ and 70 days testing by $0.2 \%$ alcoholic solution of phenolphthalein spayed to the fracture surface obtained by splitting of cylindrical specimens. In addition, on a second series of specimens exposed at the same conditions for the same periods, the height of water capillary absorption was measured after immersion in colored (by a small amount of fluorescein) water for one week. For this measure, the specimens were split and the thickness of saturated by colored water layer was determined on the fracture surface under ultraviolet light in the same way as the carbonation depth. 


\section{Results and Discussion}

\subsection{Drying}

Figure 1 presents the loss of weight per unit of exposed surface of both types of cylindrical specimens during drying. The first observation is that the loss of weight, through the free (circular) surface of concrete, is between 2 and 2.5 times higher than that then that through the cast (cylindrical) surface for the different drying conditions. This happens because the surface layer of concrete has higher water content than the bulk material because of a small bleeding after casting.

The second observation is that drying at $80^{\circ} \mathrm{C}$ for 14 days eliminates an amount of water between 2 and 2.5 times higher than that at $45^{\circ} \mathrm{C}$ for 14 days or at $20^{\circ} \mathrm{C}$ and $50 \% \mathrm{RH}$ for 87 days.

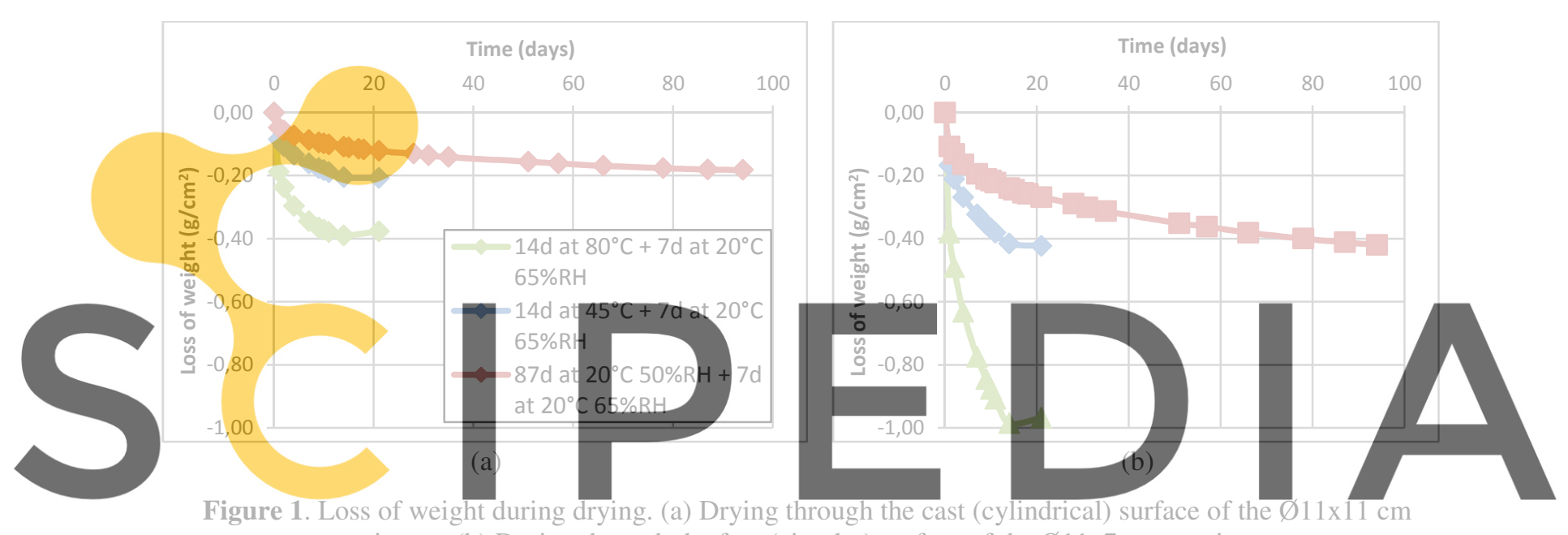

Figure 1. Loss of weight during drying. (a) Drying through the cast (cylindrical) surface of the
specimens. (b) Drying through the free (circular) surface of the $\varnothing 11 \mathrm{x} 7 \mathrm{~cm}$ specimens.

Register for free at https//www.scipedia.com to download the version without the watermark

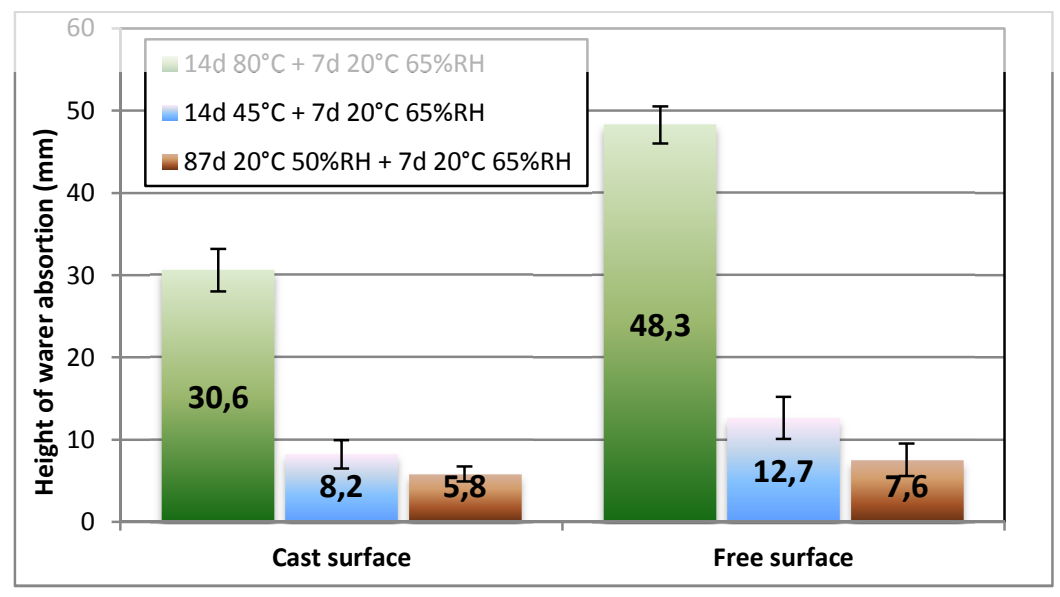

Figure 2. Height of water absorption at the end of drying.

The stronger or weaker elimination of water, according to the type of exposed surface (free or cast) and the drying condition, leads to higher or lower height of water capillary absorption 
at the end of drying (Figure 2). However, the height of water absorption through the free surface is only between 1.3 and 1.5 times higher than that through the cast surface while the loss of water was between 2.0 and 2.5 times higher (Figure 1), leading to the conclusion that the surface layer of concrete presents differences in porosity and in porous size distribution comparatively to the bulk concrete. In fact, the breeding of concrete on the free surface leads to higher porosity and probably larger porous size distribution than in the bulk concrete.

The differences in porosity and in porous size distribution could be considered also to explain the significant difference of height of water absorption after $45^{\circ} \mathrm{C}$ drying for 14 days comparatively to that after $20^{\circ} \mathrm{C}$ and $50 \% \mathrm{RH}$ drying for 87 days (Figure 2) even if in both cases the loss of weight per unit of exposed surface at the end of drying is almost the same (Figure 1). In fact, at the end of $20^{\circ} \mathrm{C}$ and $50 \% \mathrm{RH}$ drying the concrete is more than 2 months older than that at the end of $45^{\circ} \mathrm{C}$ drying. During this time, the cement hydration progresses leading generally to lower porosity and to smaller porous size distribution.

\subsection{Accelerated Carbonation}

Figure 3 presents the carbonation depth during accelerated tests of both types of specimens for different drying conditions. It should be noted that the carbonation depth is negligible before carbonation test $\left(0 \mathrm{~mm}\right.$ for $80^{\circ} \mathrm{C}$ and $45^{\circ} \mathrm{C}$ drying and less than $0.5 \mathrm{~mm}$ for $20^{\circ} \mathrm{C}$ and $50 \%$ RH drying). It can be seen also that, in all cases, the carbonation depth progresses almost linearly with the square root of testing time, consequently a carbonation rate can be calculated

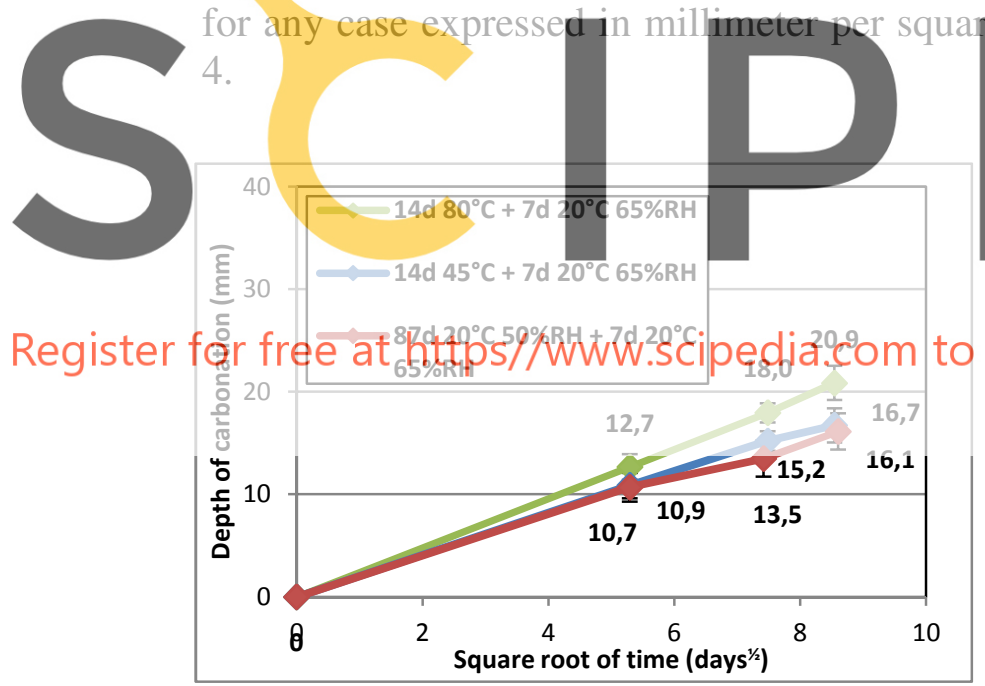

(a)

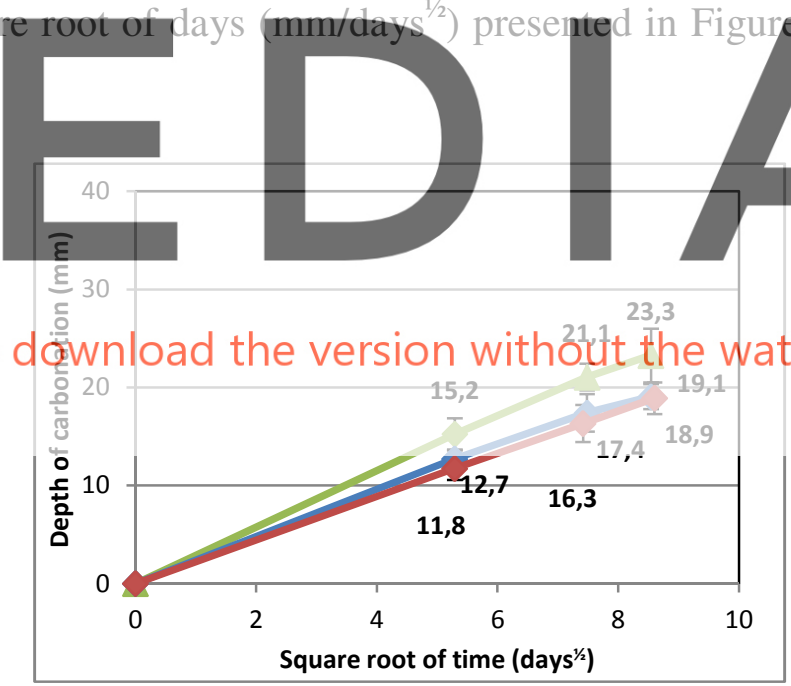

(b)

Figure 3. Carbonation depth as a function of square root of testing time (a) Carbonation through the cast (cylindrical) surface of $\varnothing 11 \times 11 \mathrm{~cm}$ specimens. (b) Carbonation through the free (circular) surface of the $\varnothing 11 \times 7 \mathrm{~cm}$ specimens.

The carbonation rate is higher through the free surface and after $80^{\circ} \mathrm{C}$ drying but is far from being proportional to the loss of water per unit of exposed surface during drying or to the height of water absorption at the end of drying. In fact, firstly the carbonation rate of specimens exposed du $\mathrm{CO}_{2}$ through the free surface is only $13-19 \%$ higher than that through the cast surface for the different drying conditions. Secondly, the carbonation rate after $80^{\circ} \mathrm{C}$ 
drying for 14 days is only $22-23 \%$ higher than that after $45^{\circ} \mathrm{C}$ drying for 14 days. Thirdly, the rate of carbonation obtained after $45^{\circ} \mathrm{C}$ drying is slightly higher (3 to $7 \%$ ) to that obtained after $20^{\circ} \mathrm{C}$ and $50 \% \mathrm{RH}$ drying for 87 days. These values allow to conclude that, firstly, a strong drying cycle $\left(\right.$ at $80^{\circ} \mathrm{C}$ ) before accelerated carbonation tests has globally stronger influence on the carbonation rate than the type of the exposed surface (free or cast) and, secondly, the progress of hydration during the longer drying at $20^{\circ} \mathrm{C}$ and $50 \% \mathrm{RH}$ does not have a very important influence on carbonation rate.

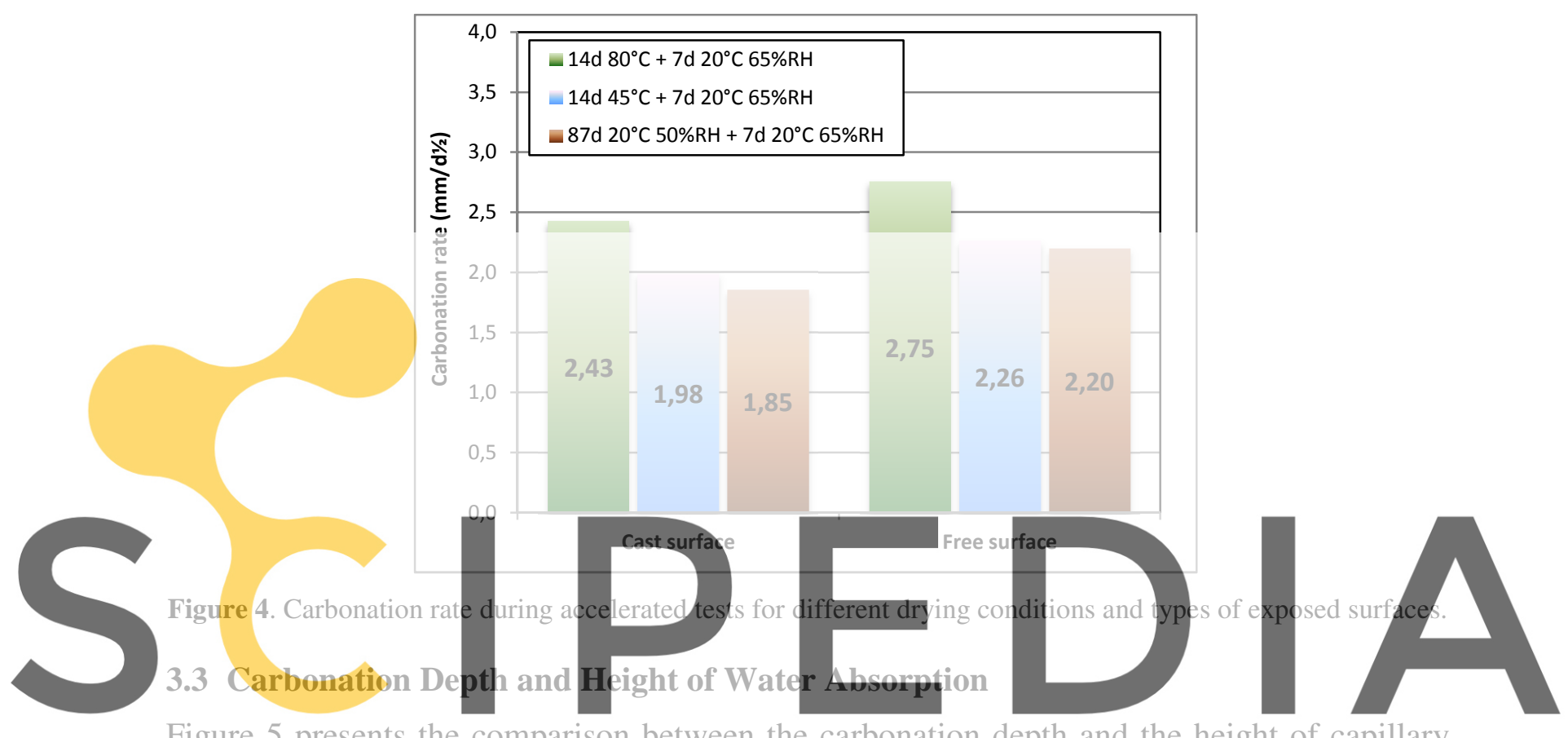

Figure 5 presents the comparison between the carbonation depth and the height of capillary

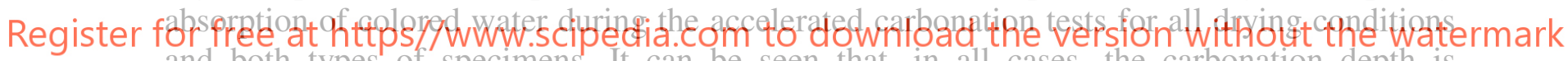
and both types of specimens. It can be seen that, in all cases, the carbonation depth is systematically lower than the height of water absorption, leading to the conclusion that, for our tests, the carbonation occurs only into the unsaturated layer of concrete.

It can be seen also that the height of water absorption increases during accelerated tests. This means that the unsaturated layer of concrete becomes thicker during testing. This is particularly interesting in the light of the fact that carbonation reaction releases water (Verbeck, 1958; Parrot, 1991) and that the specimens didn't present any loss of weight during testing, rather a gain of weight. Taking into account that there is not any similar observation in literature, we can explain these results considering, firstly, the carbonation-induced changes in porosity and in porous size distribution (Galan, 2013; Auroy, 2018) leading to higher capillary absorption and, secondly, that moisture redistribution takes place in concrete during and because carbonation. In fact, Johannesson and Ulgenannt (Johannesson, 2001) based on sorption-desorption isotherms have concluded that well-carbonated cement mortar requires higher energy to absorb water molecules at its material surfaces accelerating the desorption isotherm and holding less water comparatively to noncarbonated cement mortar. 


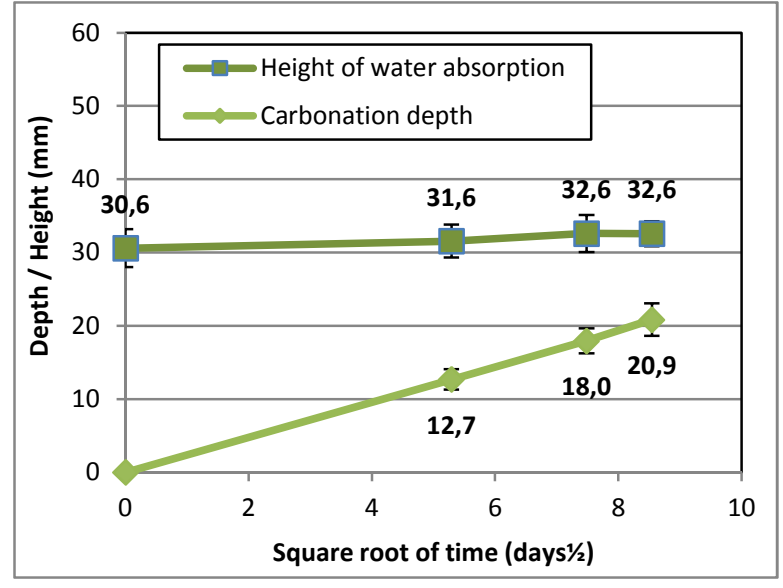

(a)
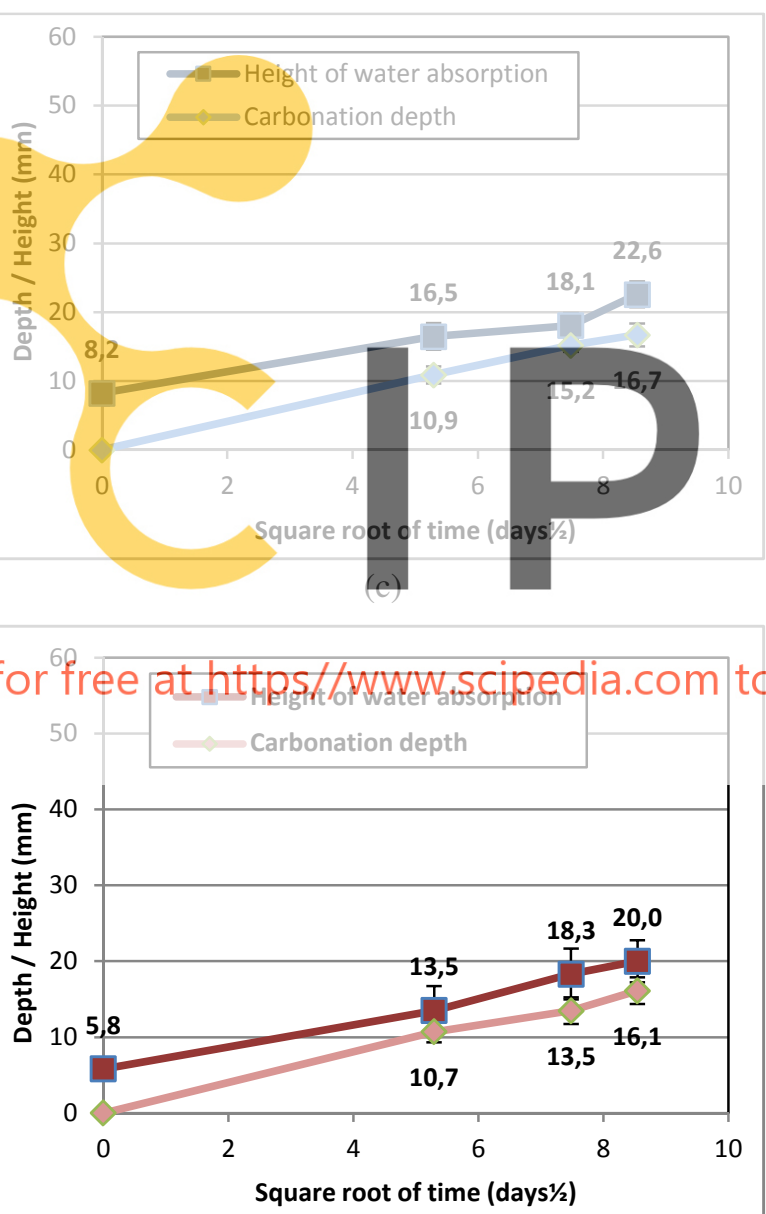

(e)

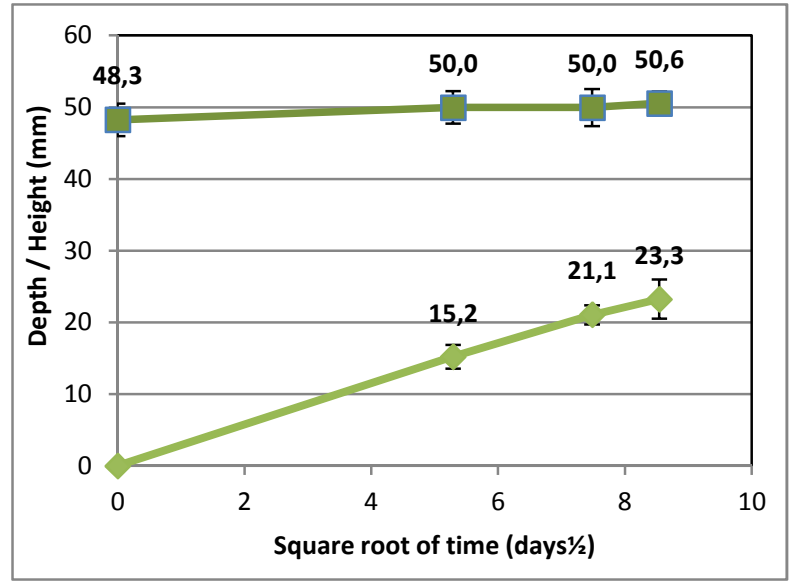

(b)
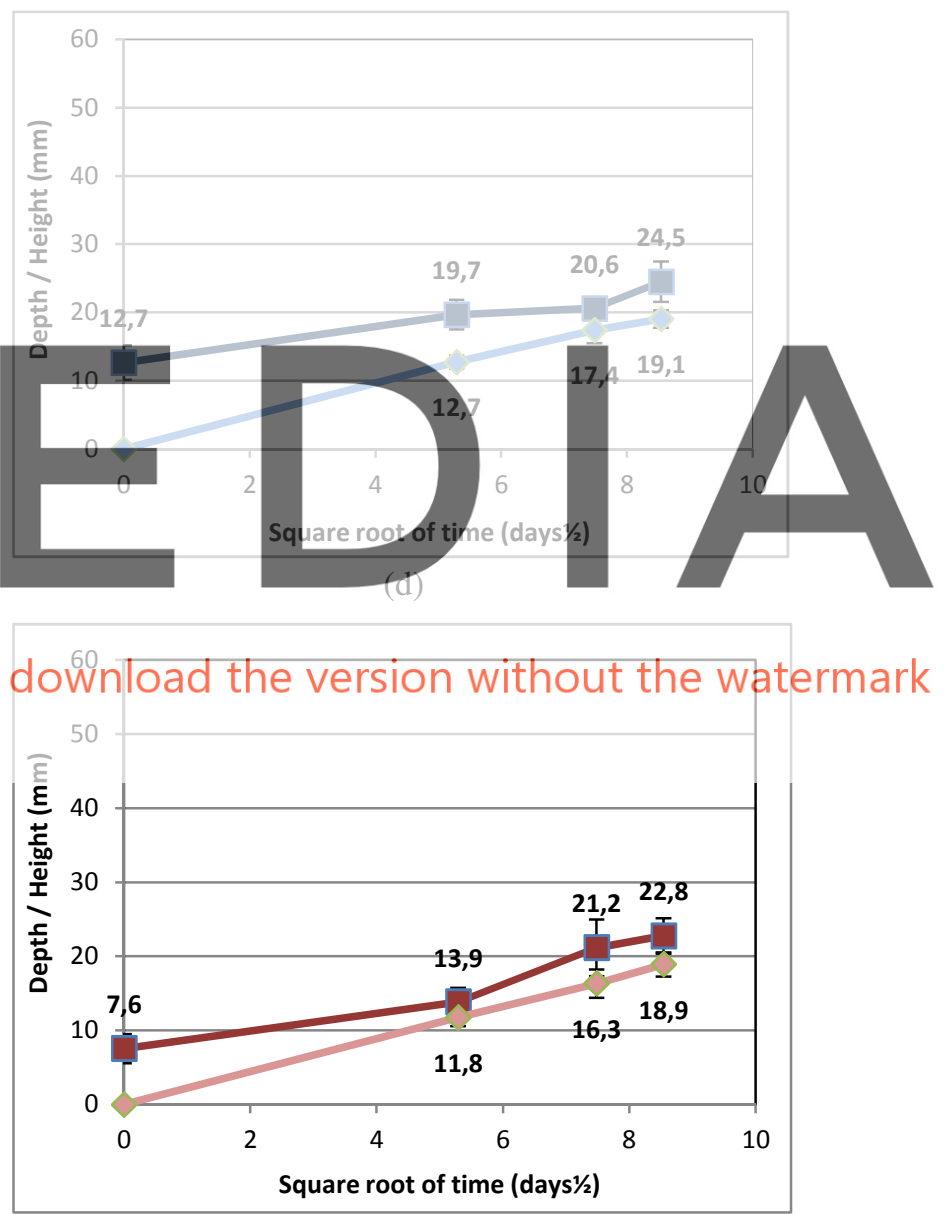

(f)

Figure 5. Carbonation depth and height of water absorption as a function of square root of testing time. (a)

Through the cast surface after $80^{\circ} \mathrm{C}$ drying for 14 days. (b) Through the free after $80^{\circ} \mathrm{C}$ drying for 14 days. (c)

Through the cast surface after $45^{\circ} \mathrm{C}$ drying for 14 days. (d) Through the free after $45^{\circ} \mathrm{C}$ drying for 14 days. (e) Through the cast surface after $20^{\circ} \mathrm{C}$ and $50 \% \mathrm{RH}$ drying for 87 days. (f) Through the free after $20^{\circ} \mathrm{C}$ and $50 \%$ RH drying for 87 days. 
The increasing of the height of water absorption follows mainly a proportional progression with the square root of testing time, allowing the determination of a rate of height increasing of water absorption during accelerated tests, expressed, just as the rate of carbonation depth, in millimeters per square root of days $\left(\mathrm{mm} /\right.$ days $\left.^{1 / 2}\right)$ presented in Figure 6.
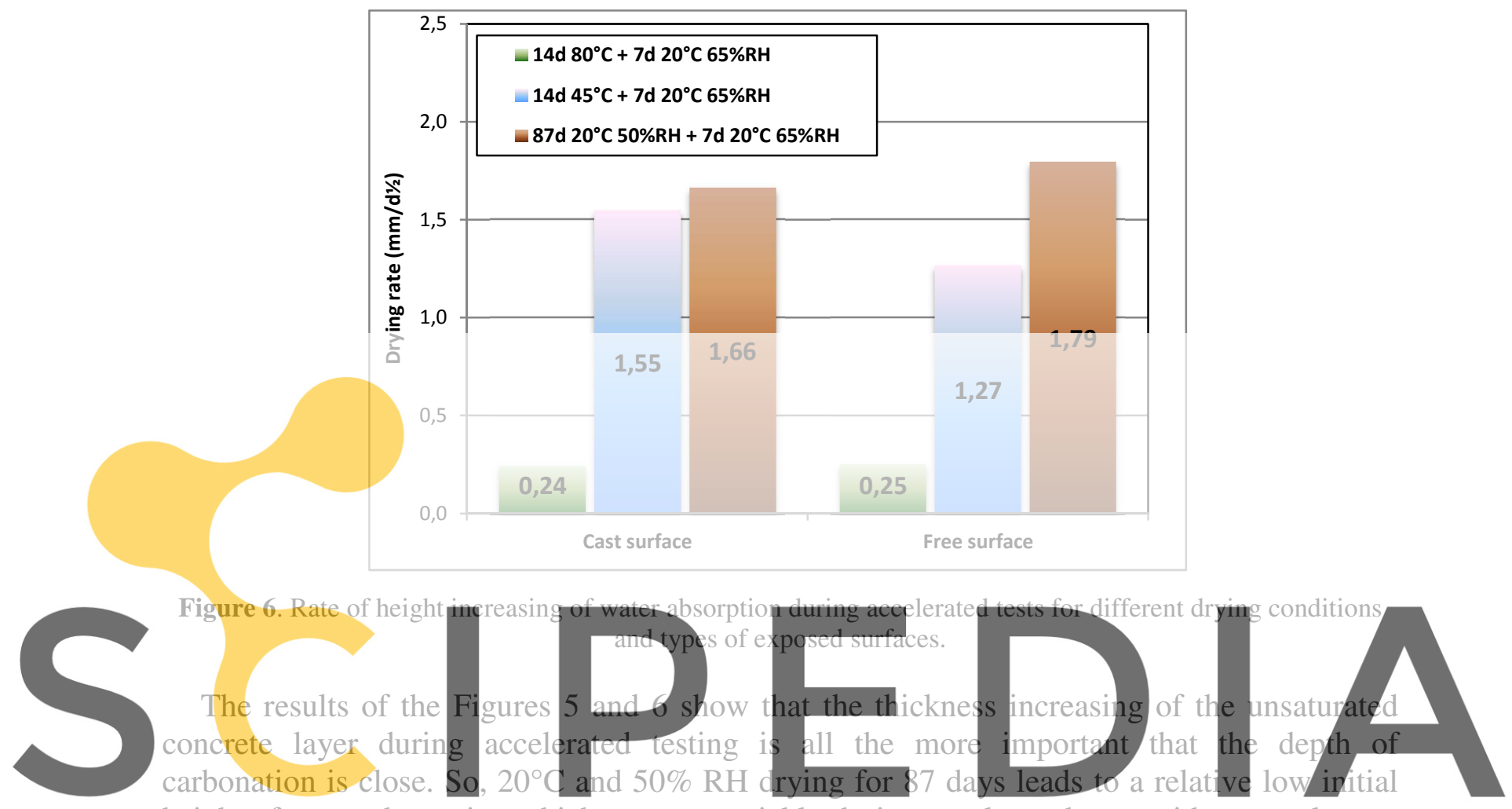

height of water absorption which progress quickly during accelerated tests with a rate close to

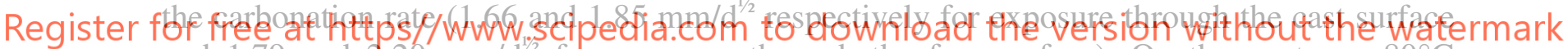
and 1.79 and $2.20 \mathrm{~mm} / \mathrm{d}^{2 / 2}$ for exposure through the free surface). On the contrary, $80^{\circ} \mathrm{C}$ drying for 14 days leads to a relative high initial height of water absorption which progress slowly during accelerate tests staying away from the carbonated layer.

\section{Conclusions}

Accelerated carbonation tests were carried out after three different drying conditions through the cast and the free surface of specimens made with a typical concrete formulation for buildings construction in the 50's and the 60's. The height of water absorption was also measured at different stages of testing and compared to the carbonation depth.

The results show that there is a significant difference in the loss of weight per unit of exposed surface through the cast and the free surface of specimens. The height of water absorption through the cast and the free surface is also significantly different. But, the drying condition before accelerated carbonation tests has more influence on the carbonation rate of concrete than the type of the exposed surface. The carbonation rates through both types of surfaces and for $45^{\circ} \mathrm{C}$ and for $20^{\circ} \mathrm{C}$ and $65 \% \mathrm{RH}$ drying are close, in accordance with literature. The carbonation rate for $80^{\circ} \mathrm{C}$ drying is significantly higher because of strong and 
deep elimination of water modifying the concrete microstructure.

The comparison of carbonation depth and height of water absorption during accelerated tests show that the height of water absorption was systematically higher than the carbonation depth. Moreover, the height of water absorption increases during testing while the carbonation releases water and the specimens present globally a gain of weight. The hypothesis of moisture redistribution in concrete during accelerated carbonation tests was advanced to explain the increase of the unsaturated layer thickness in concrete. However, more tests are necessary to validate this hypothesis starting with the determination of the water quantity absorbed till saturation of concrete at each stage of accelerated tests in comparison with the loss of water at the end of drying. To the same end it would be also interesting to follow the carbonation rate and the height of water absorption beyond 70 days in order to identify what happens when the carbonation depth reaches the thickness of unsaturated concrete.

\section{ORCID}

Jean Louis Gallias: https://orcid.org/0000-0002-4354-9226

Bruno Fiorio: https://orcid.org/0000-0003-3039-6339

Yunyun Tong: https://orcid.org/0000-0002-1078-7017

\section{References}

NF EN 206 (2014). Béton - Spécification, performance, production et conformité.

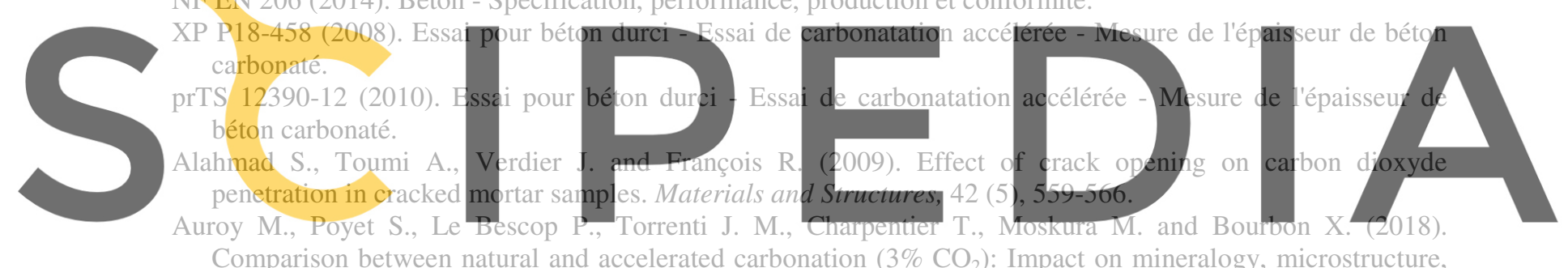

Comparison between natural and accelerated carbonation $\left(3 \% \mathrm{CO}_{2}\right)$ : Impact on mineralogy, microstructure,

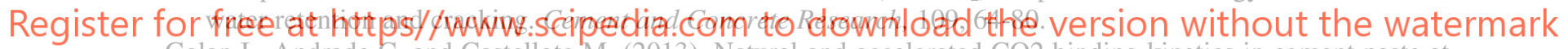

Galan I., Andrade C. and Castellote M. (2013). Natural and accelerated CO2 binding kinetics in cement paste at different relative humidities. Cement and Concrete Research, 49, 21-28.

Fattuhi, N. I. (1988). Concrete carbonation as influenced by curing regime. Cement and Concrete Research, 18(3), 426-430.

Johannesson B. and Ulgenannt P. (2001). Microstructural changes caused by carbonation of cement mortar. Cement and Concrete Research, 31, 925-931.

Parrot L. J. (1996). Some effects of cement and curing upon carbonation and reinforcement corrosion in concrete, Materials and Structures, 29 (3), 164-173.

Parrot L. J. (1991). Carbonation moisture and empty pores, Advances in Cement Research, 4, 111-118.

Verbeck G. J. (1958). Carbonation of hydrated Portland cement, ASTM Special Technical Publication 205, 1736. 